\title{
Direct Oxide Reduction (DOR) Solvent Salt Recycle in Pyrochemical Plutonium Recovery Operations
}

K. W. Fife

D. F. Bowersox

C. C. Davis

E. D. McCormick

\section{DISCLAIMER}

\footnotetext{
This report was prepared as an account of work sponsored

employees, makes any warranty, States Government nor any an agency of the United Staces bility for the accuracy, completeness, or implied, or assumes any thereof, nor any of their process disclosed, or represents that its usefulness of any information legal liability or responsjmanufacturer, or specific commercial product not infringe privately owned , product, or mendation, or favorise does not necessarily process, or service by trade rights. Referand opinions of auth by the United States Gonstitute or imply its endorse, trademark, United States Governmors expressed herein do novernment or any agency therement, recomStates Government or any agency thereof necessarily state or thereof. The views
}

\section{DE87 006314}


DIRECT OXIDE REDUCTION (DOR) SOLVENT SALT RECYCLE

IN PYROCHEMICAL PLUTONIUM RECOVERY OPERATIONS

by

K. W. Fife, D. F. Bowersox, C. C. Davis, and E. D. McCormick

\section{ABSTRACT}

One method usied at Los Alamos for producing plutonium metal is to reduce the oxide with calcium metal in molten $\mathrm{CaCl}_{2}$ at $850^{\circ} \mathrm{C}$. The solvent $\mathrm{CaCl}_{2}$ from this reduction step is currently discarded a low-level radioastive waste because it is saturated with the reaction by-product, $\mathrm{CaO}$. We have developed and demonstrated a molten salt technique for rechlorinating the $\mathrm{CaO}$, thereby regenerating the $\mathrm{CaCl}_{2}$ and incorporating solvent recycle into the batch $\mathrm{PuO}_{2}$ reduction process. We discuss results from the process development experiments and present our plans for incorporating the technique into an advanced design for semfcontinuous plutonium metal production.

INTRODUCTION

The Plutonfum Metal Technology Group at Los Alamos (MST-13) routinely uses batch pyrochemical unft operations to produce and purffy plutonfum metal from a variety of impure feed sources. ${ }^{1}$ These pyrochemfcal operations consist of controlling oxidation and reduction reactions (efther chemical or electrochemical) between plutonium metal and its compounds in suitable molten chloride salts.

One method for praducing plutonium metal from its oxide is to chemically reduce the oxide with calcium meral in molten $\mathrm{CaCl}_{2}$ at $850^{\circ} \mathrm{C}$. This process is called direct oxide reduction (DOR) and proceeds according to the general reaction ${ }^{2}$

$\mathrm{PuO}_{2}+\mathrm{Ca}^{\circ} \frac{\mathrm{CaCl}_{2}}{850^{\circ} \mathrm{C}} \mathrm{Pu}^{\circ}+\left(\mathrm{CaCl}_{2} \cdot 2 \mathrm{CaO}\right)$ 
The DOR process is a batch operation in which the $\mathrm{CaCl}_{2}$ acts as a heat sink during the exothermic reduction of $\mathrm{PuO}_{2}$, provides a medium to control the rate of reaction, and dissolves the $\mathrm{CaO}$ by-product to approximately $18 \mathrm{~mol}$.

The process does not perform any product purification, however, and impure reagents will result in impure metal product.

Because of the limited solubility of $\mathrm{CaO}$ in $\mathrm{CaCi}_{2}$, the solvent salts are discarded as low-level radioactive waste after each reduction. Developing a procedure to regenerate the spent salis offers numerous advantages; ${ }^{3}$ briefly they include
- reduction in process waste from DOR,
- improvement in overall process yields,
- potential for producing a pure solvent salt,
o increased possibility for producing a pure plutonium product from pure reagents, and
o aid in the development of a process for semicontinuous plutonium metal production.

In a research setting we have developed and demonstrated a technique to regenerate spent DOR salt on a batch basis. We have also performed more than a hundred oxide reductions using regenerated salt with essentially the same DOR process yield obtalned by our production DOR process. We feel that this constitutes a sufficlent data base to fllustrate the ieasibility of salt regeneration and recycle on a batch basis.

In theory, the regeneration of spent DOR salts could be accomplished through any of three approaches: the electrolytic reduction of $\mathrm{CaO}$ and subsequent recovery of the calctum metal, 4 precipitation of $\mathrm{CaO}$, or the chemical conversion of $\mathrm{CaO}$ to $\mathrm{CaCl}_{2}$ using an appropriate chlorinating agent. Preliminary work at Argonne National Laboratory on the electrolytic reduction of $\mathrm{CaO}$ was promising, but it was felt too much time was required for proper cell design and development. 
Precipitation studies were unsuccessful because of poor phase separation and incomplete $\mathrm{CaO}$ solute removal from the $\mathrm{CaCl}_{2}$ solvent. The final approach, $\mathrm{CaO}$ chlorination to $\mathrm{CaCl}_{2}$, appeared promising from initial experiments. 5

Experiments designed to chlorinate $\mathrm{CaO}$ used several potential. chlorinating agents. Those agents that failed because of either incomplete chlorination or contamination with unwanted impurities were ammonium chloride and carbon tetrachloride. Both $\mathrm{ZnCl}_{2}$ and $\mathrm{MgCl}_{2}$ were effective reagents but both left behind their respective oxides that needed removal before the $\mathrm{CaCl}_{2}$ could be effective in DOR. Our best experience was obtained using the gaseous reagents anhydrous $\mathrm{HCl}$, chlorine and phosgene $\left(\mathrm{COCl}_{2}\right)$.

Regeneration experiments on synthetic, spent DOR salts $\left(\mathrm{CaCl}_{2}-10 \mathrm{wt} \% \mathrm{CaO}\right.$ or $\mathrm{CaCl}_{2}-10 \mathrm{wt} \% \mathrm{CaO}-\mathrm{l}$ wt $\mathrm{Ca}^{\circ}$ ) Indicated that $\mathrm{CaO}$ alkalinity can be effectively removed by any of the three reagents (Fig. 1). But since residual oxygen $^{*}$ in the final salt will react with calcium metal in DOR to form $\mathrm{CaO}$, the residual oxygen profiles shown in Fig. 2 are better indicators of regeneration effictency. These profiles illustrate the difficulty in removing residual oxygen from the system. Regeneration with chlorine results in the best performance, followed by $\mathrm{HCl}$ and then phosgene.

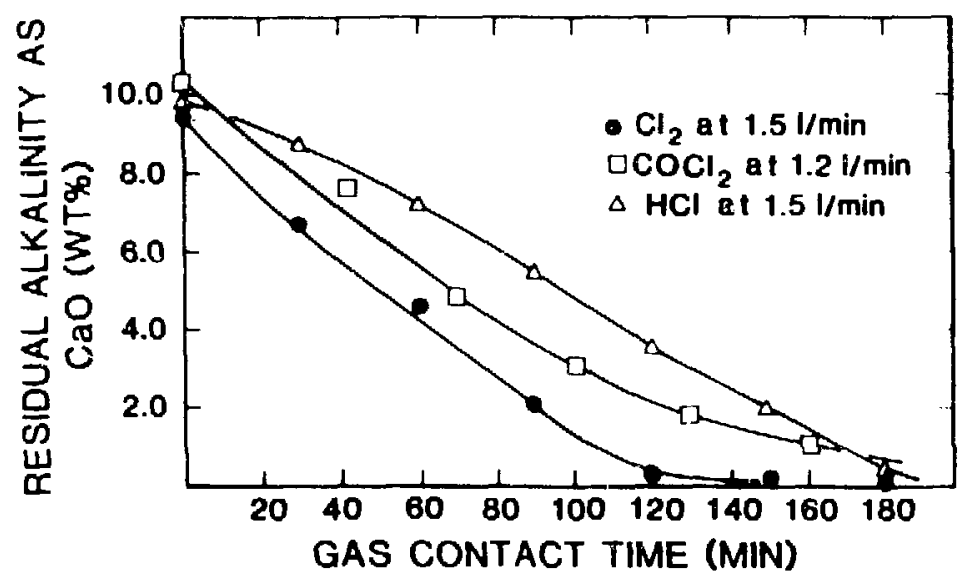

Fig. 1. Residual calcium oxide in regenerated salts.

\footnotetext{
ॠResidual oxygen values were determined by neutron activation on nonradioactive sált samples only.
} 


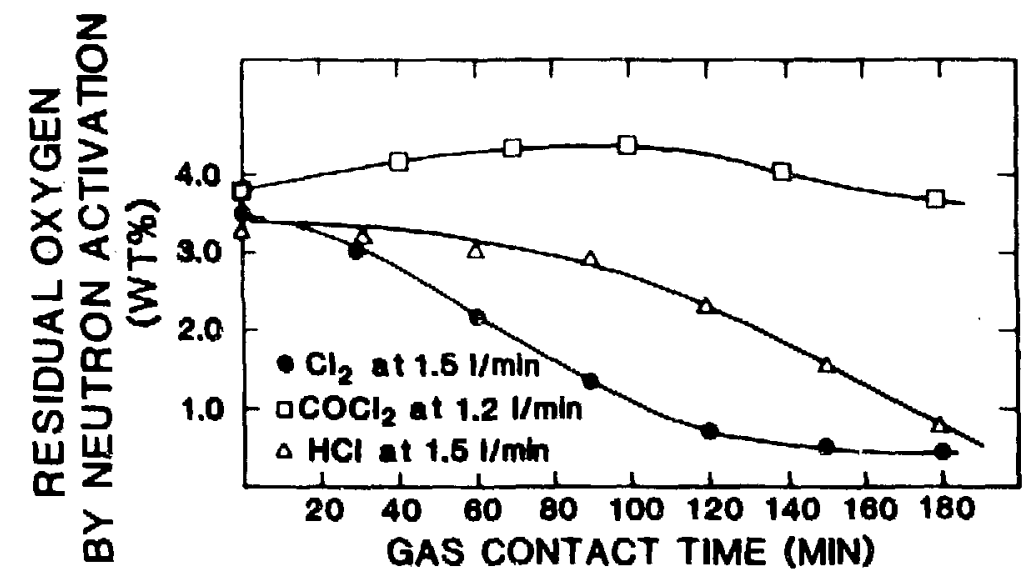

Fig. 2. Residual oxygen in regenerated salts.

As a result of these initial development experiments using synthetic, spent salts, the regeneration procedure was transferred into the plutonium environment and experiments were begun using actual spent process salts.

Because of our long-range goal to convert the DOR process from a purely batch to a semicontinuous operation by regenerating and recycling spent salts, we felt it necessary to accomplish regeneration of a full-scale DOR salt in approximately $2 \mathrm{~h}$. This regeneration time would provide the basis for advanced process development.

The success of this recycle program depends on maintaining or improving salt quality during regeneration. Plutonium is an actlve metal solvent and tends to strip metal impurities from salt (Table $I$ ). This reaction is one principal reason why the DOR process has not been able to produce a "pure" metal (>99.95\%) from "pure" reagents. If we can regenerate a salt while maintaining or improving its quality, then pure-metal production from this process is more realistic. 
TABLE I. ESTIMATES OF ELEMENT SOLUBILITIES IN PLUTONIUM AT $800^{\circ} \mathrm{C}(\operatorname{Ref} .6)$

$\begin{array}{lrrlrr}\text { Element } & \text { Atom } \% & \text { Wt\% } & \text { Element } & \text { Atom } \% & \text { Wt\% } \\ \text { Silver } & 6.5 & 2.6 & \text { Niobium } & 1.5 & 0.6 \\ \text { Aluminum } & 10.0 & 1.2 & \text { Nickel } & 45.0 & 16.7 \\ \text { Gold } & 7.0 & 5.8 & \text { Lead } & 14.0 & 12.4 \\ \text { Beryllium } & 7.0 & 0.3 & \text { Platinum } & 9.0 & 4.2 \\ \text { Bismuth } & 8.5 & 7.5 & \text { Rhenium } & 2.4 & 1.8 \\ \text { Carbon } & 2.3 & 0.1 & \text { Rhodium } & 19.0 & 9.2 \\ \text { Cadmium } & 1.0 & 0.5 & \text { Silicon } & 7.5 & 0.9 \\ \text { Cobalt } & 38.0 & 13.1 & \text { Tin } & 0.9 & 0.4 \\ \text { Chromium } & 3.3 & 0.7 & \text { Tantalum } & 0.2 & 0.1 \\ \text { Copper } & 52.0 & 22.4 & \text { Titanium } & 22.5 & 5.5 \\ \text { Iron } & 27.0 & 8.0 & \text { Thulium } & 4.1 & 2.9 \\ \text { Gallium } & 23.0 & 8.0 & \text { Vanadium } & 1.5 & 0.3 \\ \text { Hafnium } & 11.0 & 8.4 & \text { Tungsten } & 0.01 & 0.01 \\ \text { Magnesium } & 22.5 & 2.9 & \text { Yttrium } & 16.0 & 6.6 \\ \text { Manganese } & 30.8 & 9.3 & \text { Zinc } & 30.0 & 10.5 \\ \text { Molybdenum } & 2.8 & 1.1 & \text { Zirconium } & 5.4 & 2.1\end{array}$

For both plutonium and nonplutonium environments, the method used in regeneration experiments is to place the spent salt in a 15-cm-o.d. by 38-cm-tall vitrified magnesia crucible nested in a stainless steel containment can inside a stainless steel furnace tube (Fig. 3). 


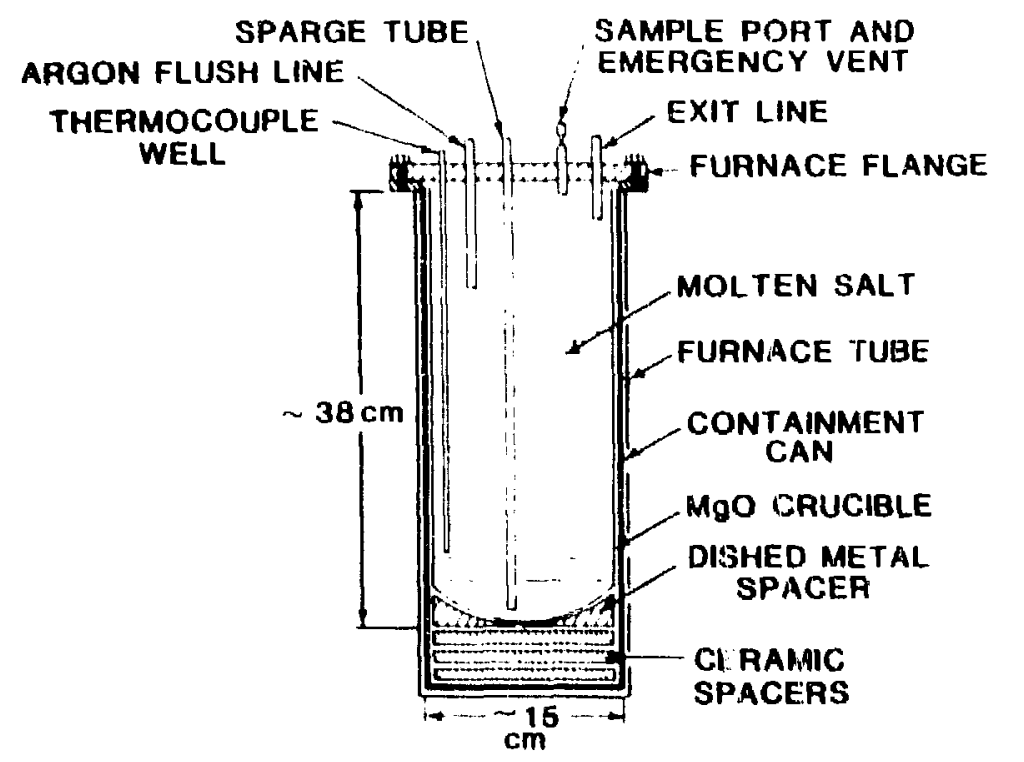

Fig. 3. Apparatus for spent-salt regeneration.

After an argon atmosphere is placed above the salt, the apparatus is resistance-heated to $850^{\circ} \mathrm{C}$ using a Lindberg model 60155 furnace. The metal is sparged for a fixed time at a flxed flow rate with either anhydrous $\mathrm{HC} 1$ or chlorine through alumina or magnesia tubing. Samples are withdrawn at selected intervals using quartz tubing to determine CaO converston profiles. After chlorination, the system is purged with argon, and the salt is vacuumtransferred ${ }^{7}$ through tantalum tubing to ambient-temperature aluminum split molds for final shaptng and cooling (Fig. 4). All off-gas from regeneration is directed through a caustic scrubber system before venting to the glovebox atmosphere. The scrubber system consists of a sertes of three pyrex bubble columns containing $4 \mathrm{M} \mathrm{KOH}$. The lead scrubber is $210 \mathrm{~cm} 0 . \mathrm{d}$, by $38 \mathrm{~cm} \mathrm{tall} \mathrm{and}$ contains 22 \&OH, followed by two scrubbers containing about $1 \&$ each.

Our recycle procedure is talentical to the production lok operating procedurc. When the regenerated salt has cooled under argon it is placed along with calctum metal and Puo, into another $15-\mathrm{cm}-0 . d$. by $38-c m-t a l l$ vitrified magnesia cructble. The crucille is placed into the equipment shown in Fig. 5 and covered with argon. A reststance furnace heats the reagents to $800^{\circ} \mathrm{C}$ and a tantalum stirrer and tantalum-nickle thernocouple well are lowered into the 
melt. Once stirring is initiated, the reaction proceeds to completion in about 5 min. After the temperature has stabilized, stirring is stopped and the stirrer and thermocouple well are removed from the melt. The system is kept at temperature for another $10 \mathrm{~min}$ to allow metal coalescence before cooling and recovery of the metal product (FIg. 6).
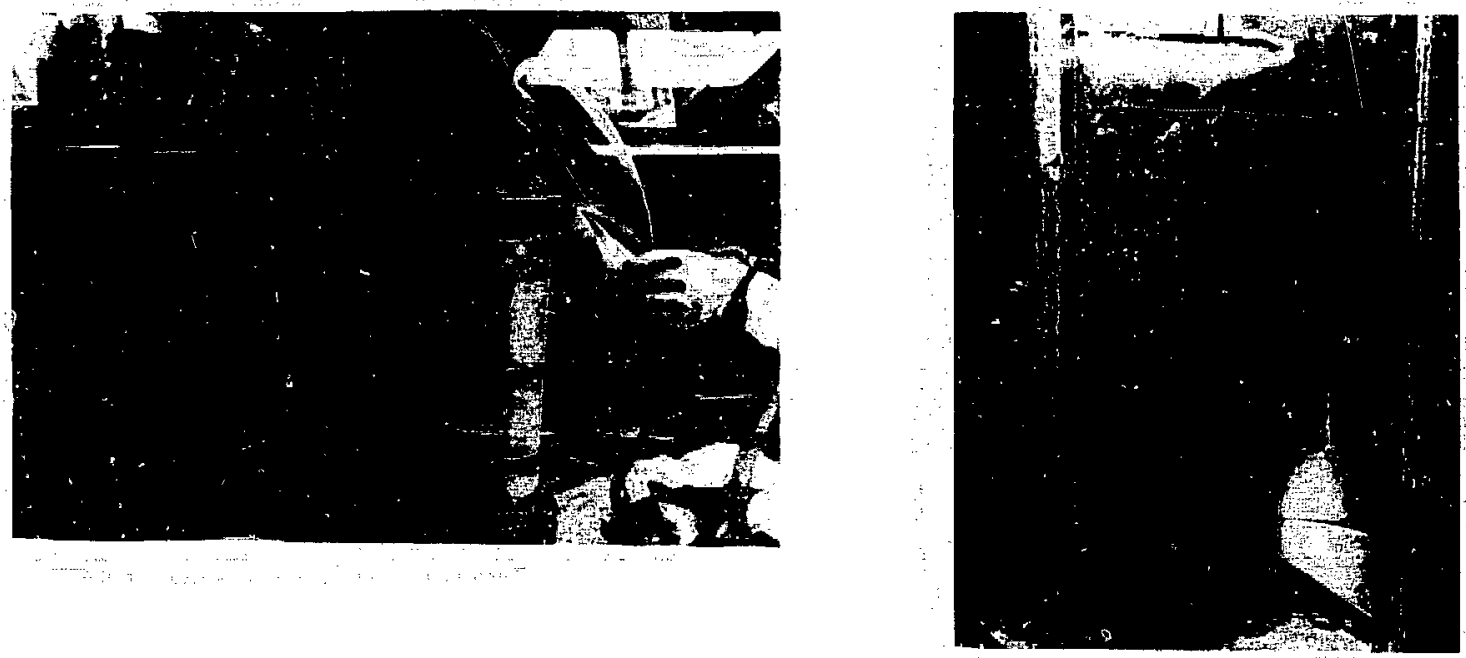

Fig. 4. Vacuum-transfer apparatus and cast of the regenerated salts.

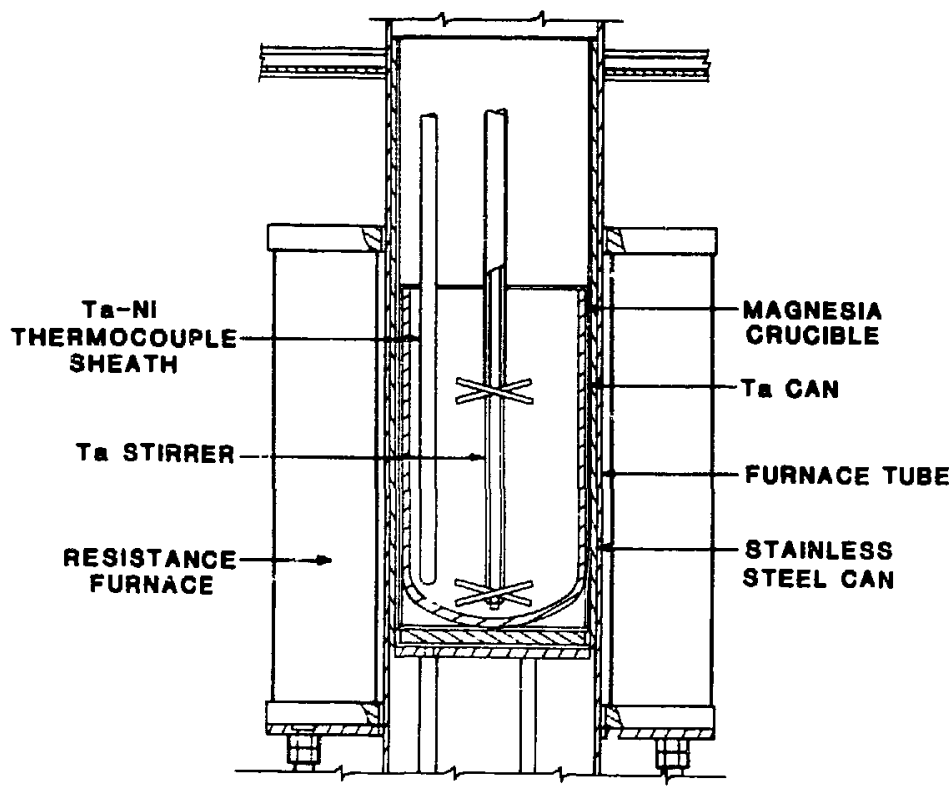

Fig. 5. DOR process equipment. 

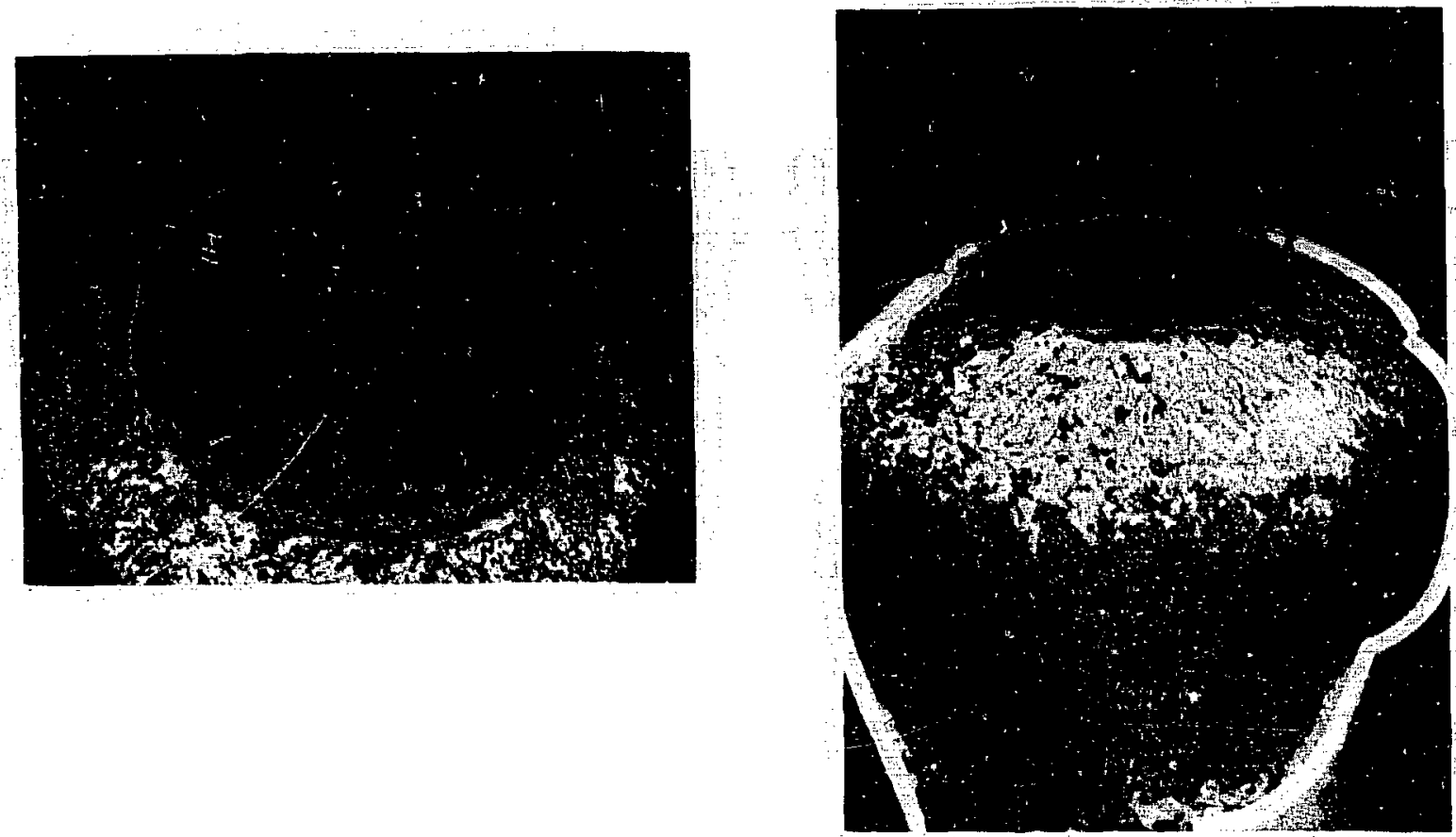

Fig. 6. DOR product buttons from regenerated salt.

RESULTS

We currently regenerate a spent DOR salt in $\sim 2 \mathrm{~h}$ with chlorine or HCl at flow rates between 3 and $5 \mathrm{l} / \mathrm{m}$. At these flow rates both reagents are effective regenerants. Chlorine, however, produces a better quality salt based on regeneration and recycle performance, and it has become our reagent of choice (Fig. 7).

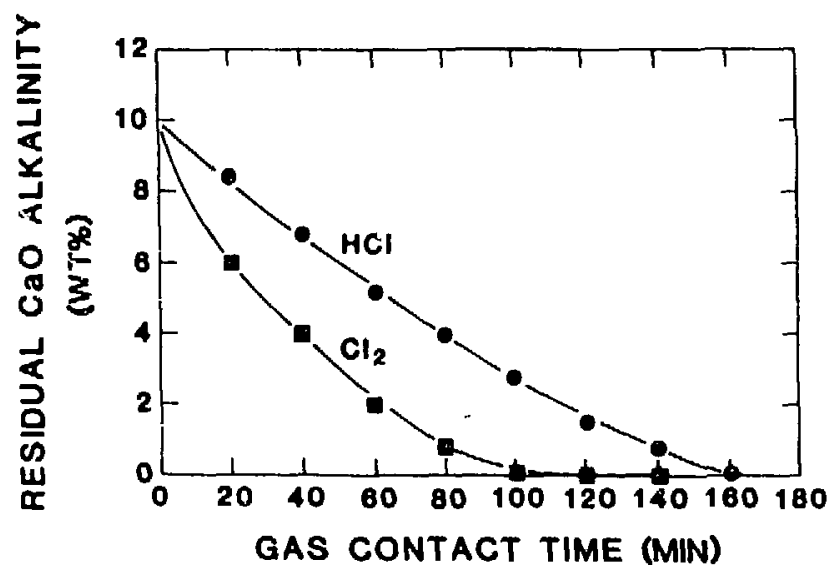

Fig. 7. Salt regeneration profiles with $\mathrm{HCl}$ and $\mathrm{Cl}_{2}$ at $4 \mathrm{l} / \mathrm{m}$. 
Minimizing or eliminating the introduction of metallic impurities during regeneration has always been an area of interest. 8 We need to maintain high quality in the regenerated salt to keep the purity of our final plutonium metal product high. The corrosive nature of chlorine on wetted ceramic parts results in elevated magnesium concentrations ( $<2000 \mathrm{ppm}$ ) in the final salt, and in aluminum concentrations approaching $300 \mathrm{ppm}$ when alumina hardware is used. In addition to these elements, we have found occasional high concentrations of stainless steel components present after regeneration (a total of 500-1000 ppm $\mathrm{Fe}, \mathrm{Cr}, \mathrm{N} i, \mathrm{Mn}$ ) and some yttria, presumably from ceramics used in the system.

We believe stainless steel impurities result from corrosion of metal hardware caused by circulation of the corrosive off-gas in the vapor space above the salt. We have minimized this corrosion with several minor system changes. We replaced the top furnace flange with either Hastelloy $\mathrm{C} 276$ or Inconel 625, raised the magnesia vessel as high as possible in the furnace tube, diluted the chlorine regenerant with argon, and introduced another argon flush line to the furnace to sweep the vapor space and force the off-gas out of the system quickly (Fig. 3). We could reduce the alumina concentration by swltching to an all-magnesia system, but have yet to find a commercial supplier of reliable magnesia tubing. The magnesia contamination continues, however, and reduces to magnesium metal during the recycle step. Some volatilizes and collects in the cooler vapor space of the furnace, and some collects with the plutonium metal product, forming a calclum-magneslum-plutonium layer on the metal surface (Fig. 8).
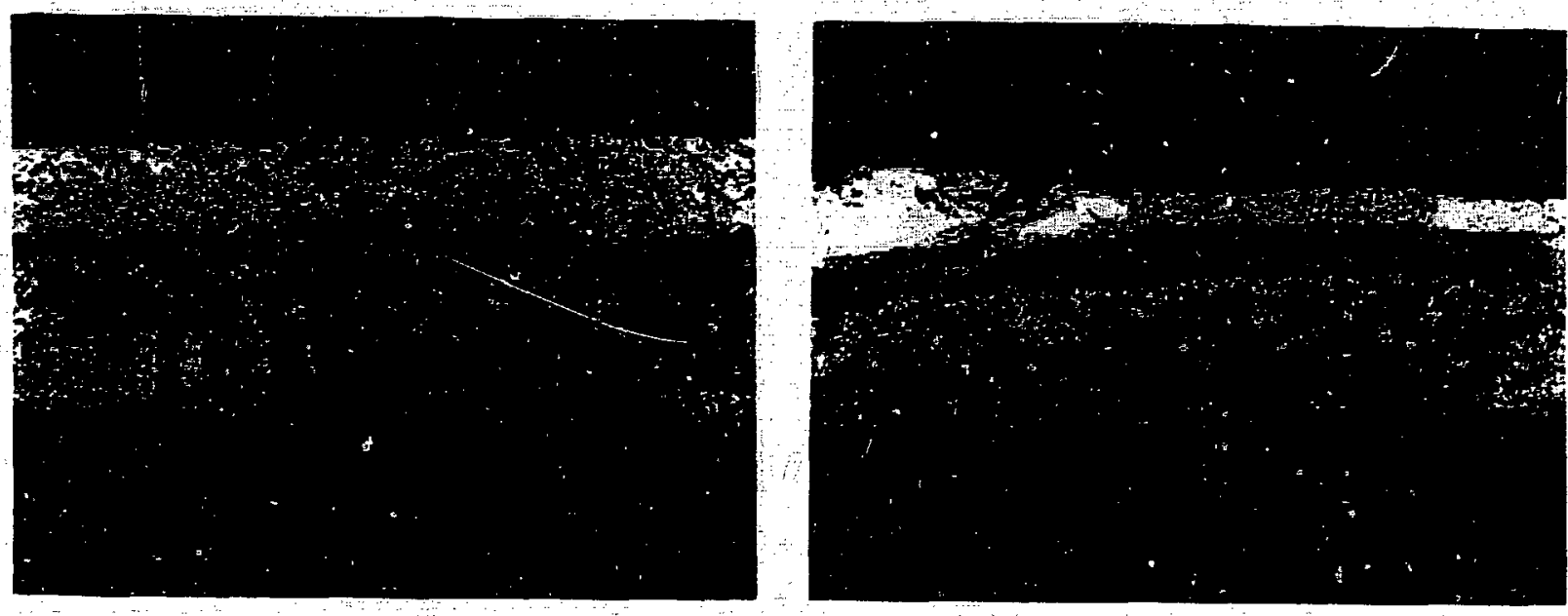

Fig. 8. Cross section of DOR button (oxidized to illustrate phases). 
The purities of some typical regenerated salts are listed in Tables II and III. Both tables reflect $2-h$ salt regeneration with diluted chlorine $\left(\mathrm{Cl}_{2}: \mathrm{Ar}\right.$ ratio of 3:2), a magnesla reaction vessel, and stainless steel containment vessels. Table II, however, illustrates regeneration with a magnesia sparge tube and a top furnace flange constructed of Hastelloy $C 276$. ${ }^{*}$ Table III lists salt purity data using an alumina sparge tube and a top furnace flange constructed of Inconel 625 . $^{*}$

We are encouraged by these data since the only impuritias we are adding to the salts are those resulting from ceramic corrosion or dissolution during reganeration. We are continuing to investigate parameter changes in hopes of further lowering these values, but realize that the optimum process may include ceramic impurities in the final salt. We are also continuing to investigate potentlal metal candidates for vessel construction but have yet to find a material superior to vitrified magnesia.

The technique we have developed to regenerate spent DOR salts has been very effective in reducing process waste on a research scale. As a result of this successful development program, we initiated a short-term production demonstration in our research area aimed at evaluating the technique on a daty basis while performing regeneration and recycle. We rotated two salts between regeneration and recycle for a total of five campaigns; each campaign ended when the total product metal from oxide reduction approached $6 \mathrm{~kg}$ - the amount necessary for the downstream processes ingot casting and purffication by electrorefining.

Resu1ts of these five campaigns are presented in Table IV.

Nominal composition of Hastelloy $\mathrm{C} 276$ (wt\%): $\mathrm{N} 1,16 \mathrm{Cr}, 15 \mathrm{Mo}, 5 \mathrm{Fe}$, $3.7 \mathrm{~W}, 1.4 \mathrm{Co}, \mathrm{IMn}$

**

Nominal composition of Incone1 625 (wt\%): $\mathrm{Ni}, 20 \mathrm{Cr}, 9 \mathrm{Mo}, 5 \mathrm{Fe}$, $+(\mathrm{Nb}+\mathrm{Ta})$ 
TABLE II. SALT PURITY RESULTS FOR SOME REGENERATED SALTS USING MgO-WETTED HARDWARE AND A HASTELLOY C276 FURNACE HEAD

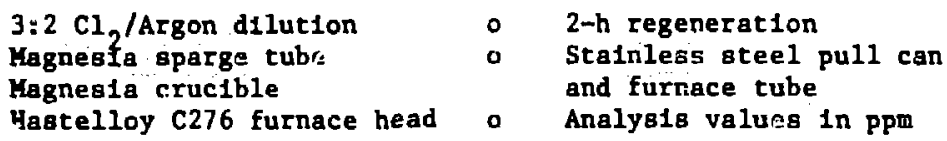

Alkalinity As $\mathrm{CaO}$

Ruri Number

$\begin{array}{lllllllll}\text { A1 } & B & \mathrm{Cr} & \mathrm{Cu} & \mathrm{Fe} & \mathrm{Mg} & \mathrm{Mn} & \mathrm{N} 1 & \mathrm{Ta}\end{array}$

\begin{tabular}{|c|c|c|c|c|c|c|c|c|c|c|c|}
\hline 85-1nitial & 30 & $<3$ & 4 & 3 & 20 & 40 & 5 & 4 & $<100$ & $\overline{60}$ & 7.39 \\
\hline 85-final & 30 & $<3$ & 4 & 3 & 50 & 60 & 5 & $<4$ & $<100$ & 50 & 3.85 \\
\hline 86-1nitial & 12 & $<3$ & $<4$ & 3 & 20 & 20 & $<1$ & $<4$ & $<100$ & 60 & 7.01 \\
\hline 86-final & 15 & $<3$ & 5 & 2 & 20 & 500 & 4 & $<4$ & $<100$ & 30 & $<0.01$ \\
\hline 88-InIt1al & 4 & $<3$ & $<4$ & 1 & 12 & 15 & $<1$ & $<4$ & $<100$ & 30 & 5.86 \\
\hline 88-fina1 & 12 & $<3$ & $<4$ & 1 & 8 & 600 & $<1$ & $<4$ & $<100$ & 50 & $<0.01$ \\
\hline 90-Initial & 5 & $<3$ & 4 & 25 & 100 & 40 & 1 & $<4$ & $<100$ & 20 & 5.69 \\
\hline 90-f1na1 & 5 & $<3$ & io & 2 & 100 & 1000 & 2 & $<4$ & $<100$ & 20 & 0.02 \\
\hline 91-1nitial & 4 & $<3$ & $<4$ & 25 & 4 & 12 & $<1$ & $<4$ & $<100$ & 30 & 5.80 \\
\hline 91-final & $<4$ & $<3$ & $<4$ & 3 & 20 & 1000 & 1 & $<4$ & $<100$ & 25 & $<0.01$ \\
\hline 92-1n1tial & $<4$ & $<3$ & $<4$ & 1 & 10 & 40 & $<1$ & $<4$ & $<100$ & 20 & 7.61 \\
\hline 92-final & 10 & $<3$ & $<4$ & 1 & 100 & 4000 & 1 & $<4$ & $<100$ & 80 & 0.92 \\
\hline 93-Initial & $<4$ & $<3$ & 5 & 1 & 40 & 20 & $<1$ & $<4$ & $<100$ & 10 & 5.87 \\
\hline 93-final & $<4$ &.$<3$ & $<4$ & 1 & 8 & 600 & 4 & $<4$ & $<100$ & 10 & 0.03 \\
\hline 94-InItial & 4 & - $<3$ & $<4$ & 1 & 6 & 25 & $<1$ & $<4$ & $<100$ & 15 & 8.61 \\
\hline $94-f 1 n a 1$ & 5 & $<3$ & 4 & 40 & 40 & 100 & 1 & $<4$ & $<100$ & 15 & 0.05 \\
\hline 103-Inltial & $<4$ & $<3$ & $<4$ & 2 & 12 & 50 & $<1$ & $<4$ & $<100$ & 35 & 6.03 \\
\hline 103-final & 4 & $<3$ & 4 & 2 & 20 & 300 & $<1$ & $<4$ & $<100$ & 10 & 0.06 \\
\hline 106-init1a1 & 4 & $<3$ & $<4$ & 2 & 20 & 30 & $<1$ & $<4$ & $<100$ & 50 & 6.04 \\
\hline 106-final & 80 & $<3$ & 4 & 1 & 15 & 500 & 2 & $<4$ & $<100$ & 50 & 0.02 \\
\hline
\end{tabular}


TABLE III. SALT PURITY RESULTS FOR SOME REGENERATED SALTS USING $\mathrm{MgO} / \mathrm{Al}_{2} \mathrm{O}_{3}$-WETTED HARDWARE AND AN INCONEL 625 FURNACE HEAD

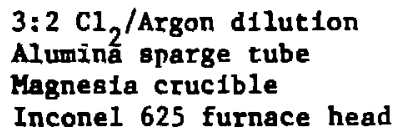

\begin{tabular}{|c|c|c|c|c|c|c|c|c|c|c|}
\hline Run Number & A1 & $\mathrm{Cr}$ & $\mathrm{Cu}$ & $\mathrm{Fe}$ & $\mathrm{Mg}$ & $\mathrm{Mn}$ & N1 & $\mathrm{Ta}$ & $\mathrm{Y}$ & $\begin{array}{c}\text { Alkalinity } \\
\text { As CaO } \\
\text { (wtz) }\end{array}$ \\
\hline 65-1nit1a1 & 85 & 5 & $<\overline{1}$ & 25 & 350 & $<1$ & 4 & $<100$ & 100 & 7.25 \\
\hline 65-final & 250 & 4 & $<1$ & 20 & 350 & $<1$ & $<4$ & $<100$ & 100 & 0.06 \\
\hline $66-\operatorname{In} 1 t 1 a 1$ & 6 & $<4$ & $<1$ & 50 & 250 & $<1$ & 4 & $<100$ & 12 & 7.72 \\
\hline 66-final & 250 & $<4$ & $<1$ & 12 & 350 & $<1$ & $<4$ & $<100$ & 40 & $<0.01$ \\
\hline 67-In1t1al & 12 & 4 & $<1$ & 25 & 40 & $<1$ & $<\dot{4}$ & $<100$ & $60^{\circ}$ & 7.03 \\
\hline 67-final & 100 & $<4$ & 1 & 10 & 3.500 & 1 & $<4$ & $<100$ & 40 & 0.08 \\
\hline 68-In1t1al & 12 & $<4$ & 1 & 10 & 12 & $<1$ & $<4$ & $<100$ & 40 & 7.29 \\
\hline 68-final & 100 & 5 & 1 & 40 & 2000 & 3 & $<4$ & $<100$ & $40^{\circ}$ & 0.04 \\
\hline 69-In1tia1 & 12 & $<4$ & 1 & 4 & 12 & $<1$ & $<4$ & $<100$ & 40 & 6.66 \\
\hline 69-final & 75 & 4 & 1 & 10 & 350 & $<1$ & $<4$ & $<100$ & 40 & $<0.01$ \\
\hline $70-\ln 1$ tial & 6 & $<4$ & $<1$ & 7 & 100 & $<1$ & $<4$ & $<100$ & 60 & 7.28 \\
\hline $70-$ final & 85 & $<4$ & $<1$ & 6 & 2500 & $<1$ & $<4$ & $<100$ & 60 & $<0.01$ \\
\hline $71-1 n 1 t 1 a 1$ & 6 & $<4$ & $<1$ & 12 & 60 & $<1$ & $<4$ & $<100$ & 60 & 6.88 \\
\hline 71-fina1 & 120 & $<4$ & $<1$ & 6 & 600 & $<1$ & $<4$ & $<100$ & 60 & $<0.01$ \\
\hline $72-\ln 1 t 1 a l$ & 6 & $<4$ & $<1$ & $<4$ & 12 & $<1$ & $<4$ & $<100$ & 60 & 6.30 \\
\hline 72-final & 250 & $<4$ & $<1$ & 25 & 500 & $<1$ & $<4$ & $<100$ & 60 & $<0.01$ \\
\hline 73-1n1t1al & 20 & $<4$ & $<1$ & 20 & 40 & $<1$ & $<4$ & $<100$ & 60 & 6.45 \\
\hline 73-fIna1 & 200 & 4 & 6 & 100 & 1000 & 12 & $<4$ & $<100$ & 60 & $<0.01$ \\
\hline $74-\ln 1 t 1 a 1$ & 40 & $<4$ & $<1$ & 6 & 35 & $<1$ & $<4$ & $<100$ & 25 & 9.56 \\
\hline 74-final & 120 & $<4$ & $<1$ & 6 & 350 & $<1$ & $<4$ & $<100$ & 60 & 0.02 \\
\hline
\end{tabular}


TABLE IV. DOR SALT RECYCLE -

RESULTS OF DEMONSTRATION ACTIVITIES

(BATCH REGENERATION AND RECYCLE)

\section{Campaign}

$\begin{array}{ccccc}\frac{1}{\text { Pure }} & \frac{2}{\text { Foundry }} & \frac{3}{\text { Foundry }} & \frac{4}{\text { Foundry }} & \frac{5}{\text { Foundry }} \\ \mathrm{PuO}_{2} & \mathrm{PuO}_{2} & \mathrm{PuO}_{2} & \mathrm{PuO}_{2} & \mathrm{PuO}_{2}\end{array}$

Feed

5.5

6.0

5.9

5.7

6.0

DOR process

yie1d, \% Pu

96.6

98.8

99.1

95.8

98.3

P1utonium to

waste, $\% \mathrm{Pu}$

2.5

1.2

0.5

1.9

1.6

* Plutonium in process, \% $\mathrm{Pu}$

0.9

0

0.4

2.3

0.1

Plutonfum to recycle, \% $\mathrm{Pu}$

1.0

0.8

0

0.4

1.3

Excess calcium,

in DOR, \%

50

30

30

20

25

Reduction in salt

and crucible

process waste,

51.2

53.8

49.5

45.4

52.7

Salt fraction in waste, \%

18.6

12.9

14.7

21.9

11.7

Crucible frac-

tion in waste, \%

81.4

87.1

85.3

78.1

88.3

Spent caustic, $\ell$

17.5

12.5

7.5

7.5

7.5

Chlorine/argon

dilution at

$3 \mathrm{l} / \mathrm{min}$ for $\mathrm{2}$

$100 \% \mathrm{Cl}_{2}$

$3: 2$

$3: 2$

$3: 2$

* This value includes nondestructive analysis error, chemical analysis variability, and plutonfum adhering to hardware (stirrers, thermocouple wells, etc.), factors that are normally not included in incremental accountability practices. 
Throughout the demonstration period (more than 50 cycles), the same two salts were used for regeneration and recycle. Overall DOR process yields were situilar to those experienced in production IOR where the salt is discarded after each use. The first campaign was a continuation of early development experiments using pure $\mathrm{PuO}_{2}$ as feed for $\mathrm{DOR}$ (to reduce process vartables), $50 \%$ excess calcium (similar to production DOR histcric use), $100 \%$ chlorine as the regenerant (historic use), and with no concerted effort to conserve reagents and further reduce waste (high excess calcium, high chlorine use, large volumes of spent caustic generated). Subsequent campaigns, however, 11lustrate our at tempts at improving the process in these areas. We have successfully reduced the excess calcium in $\mathrm{DOR}$ without affecting $\mathrm{PuO}_{2}$ reduction yields; we switched from pure $\mathrm{PuO}_{2}$ to foundry $\mathrm{PuO}_{2}$ (this impure, refractory $\mathrm{PuO}_{2}$ is historically the feed for DOR), and we began diluting the chlorine with argon and also began improving our utilization of the caustic scrubber solution.

One of the main advantages of the recycle technique is to reduce the overall spent salt waste from DOR. These five campaigns indicate that reductions in waste of around $50 \%$ are possible from the batch technique. In theory, the amount of calcium fed to DOR goes to regeneretion as either CaO or excess calcium metal. This amount needs to be bled from the process as $\mathrm{CaCl}_{2}$ to maintain a coistant salt balance in the system (assuming $100 \%$ calcium metal conversion to $\mathrm{CaCl}_{2}$ ). With $50 \%$ excess calcium in DOR, this bleed stream is close to $20 \%$; with $20 \%$ excess calcium the value 1 approximately $16 \%$. This means that the maximum reduction in process waste from DOR could be around $80-85 \%$.

Actual operating experience with this batch technique, however, increases process waste for the following reasons:

- When calculating the overall reduction in process waste for Table IV, regeneration is assumed to be a part of the DOR process. We currently discard a magnesia crucible after regeneration which is counted in the waste stream calculation and reduces its value. 
- The liquid spent caustic waste is not currently included in the process waste stream calculations. It would also reduce the value.

The ceramic vessels used in oxide reduction and regeneration occasionally fail during a run. This causes us to discard the entire salt because of the excessive contamination with stainless steel products and our inability to remove all of the Mgo crucible fragments from the salt. This Increases DOR process waste.

Other waste sources not included in the waste stream calculations consist mainly of scrubber glassware, furnıce elements, and nonplutonium metal scrap (furnace tubes, pull cans, stirrers, thermocouple wells, transfer tubes, etc.). This also increases waste.

Excess caicium metal is not completely converted to $\mathrm{CaCl}_{2}$. Buoyant calcium floating on the surface of the $\mathrm{CaCl}_{2}$ during regeneration is effectively pusined to the crucible walls when the gas stream breaks the moiten salt surface, resulting in inefficient gas/liquid contacting (Fig. 9). This redices the $\mathrm{CaCl}_{2}$ bleed stream and ultimately complicates the system from a waste disposal standpoint. Free calcium metal in waste streams is unacceptable for long-term storage because of its hydrogengeneration potential if exposed to water.

In summary, we are very encouraged by the results cf this short-term production demonstration using regenerated salts in DOR. To date, we have some data on the performance of the product plutonium metal in the downstream processes of ingot castirg and electrorefining. Currently, performance in both processes appears to be very similar to historic performance of conventional DOR product metal. 

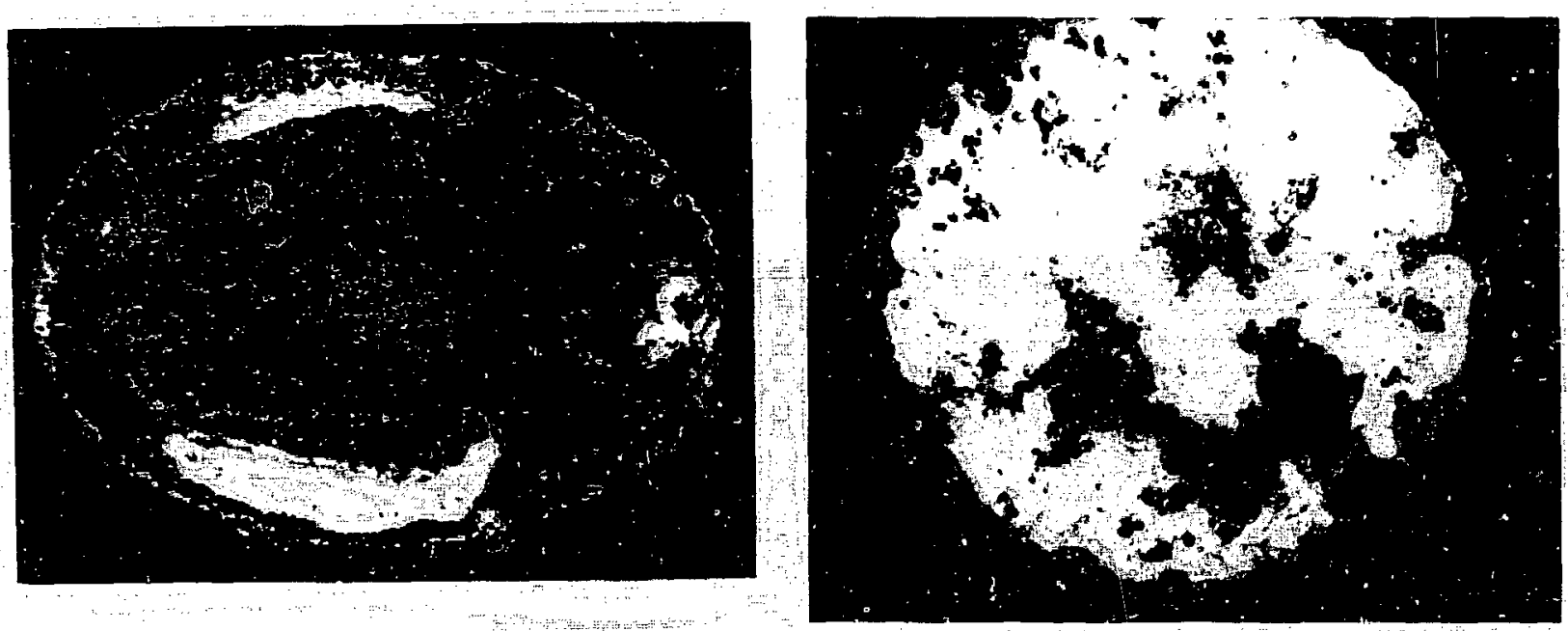

Fig. 9. $\mathrm{CaCl}_{2}$ regenerated salt with unreacted Calctum.

DOR salt regeneration and recycle is being developed as a stand-alone batch process capable of producing a reusable solvent salt for DOR. Our ability to vacuum-transfer and cast molten salts not only allows us to control the geometry of the DOR feed salt, but will be relled on in our advanced DOR processing concept. We are optimizing DOR and plan to convert the process from a batch to a semicontinuous operation. We initially plan to use three furnaces and transfer molten salt between them. This eliminates lost processing time through furnace heating and cooling (Fig. 10).

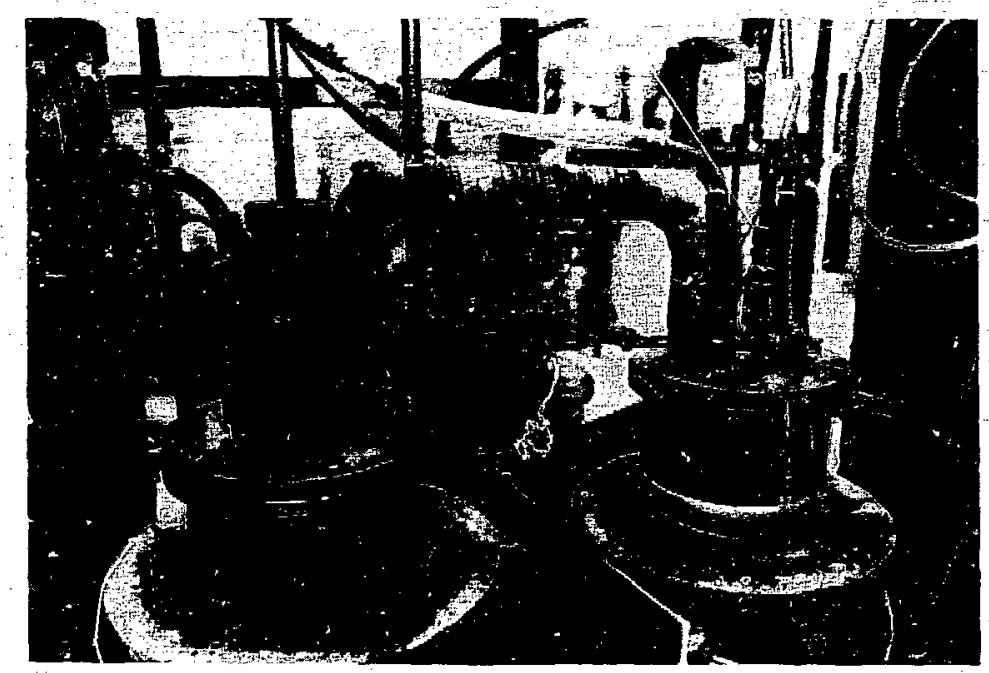

Fig. 10. Semicontinuous salt recycle and oxide reduction apparatus.

Oxide reduction will be performed in one vessel while the other two will be regeneration vessels. This is the preferred scheme because DOR is about a 
20-min operation whereas regeneration takes $\sim 2 \mathrm{~h}$. Recently we have been successful in multiple cycles of oxtde reduction using lead oxide as a substitute for $\mathrm{PuO}_{2}$ ( $\mathrm{Table} \mathrm{V).} \mathrm{We} \mathrm{accomplished} \mathrm{salt} \mathrm{transfer,} \mathrm{regeneration,}$ and salt transfer back for oxide reduction without the intermittent furnace cooling necessary in the batch process.

Table $V$ illustrates our learning curve with this new process. The important aspect of these data lies in our ability to efficlently recover product lead metal after completing successive salt cycles. Product metal recovery was accomplished primarily through cooling and subsequent product breakout. On a few occasions, however, we were successful in recovering the product by vacuum transferring and casting the molten metal.

TABLE V. RESULTS FROM THE SEMICONTINUOUS REDUCTION OF $\mathrm{Pb}_{3} \mathrm{O}_{4}$ TO LEAD METAL USING SOLVENT SALT REGENERATION AND RECYCLE

Reduction: Approximately 1/2-scale DOR with $\mathrm{Pb}_{3} \mathrm{O}_{4}$ and $\mathrm{CaCl}_{2} ; 40 \%$ excess $\mathrm{Ca}^{\circ}$

Regeneration: Chlorine at $3 \mathrm{l} / \mathrm{min}$ for $\mathrm{n} 2 \mathrm{~h}$

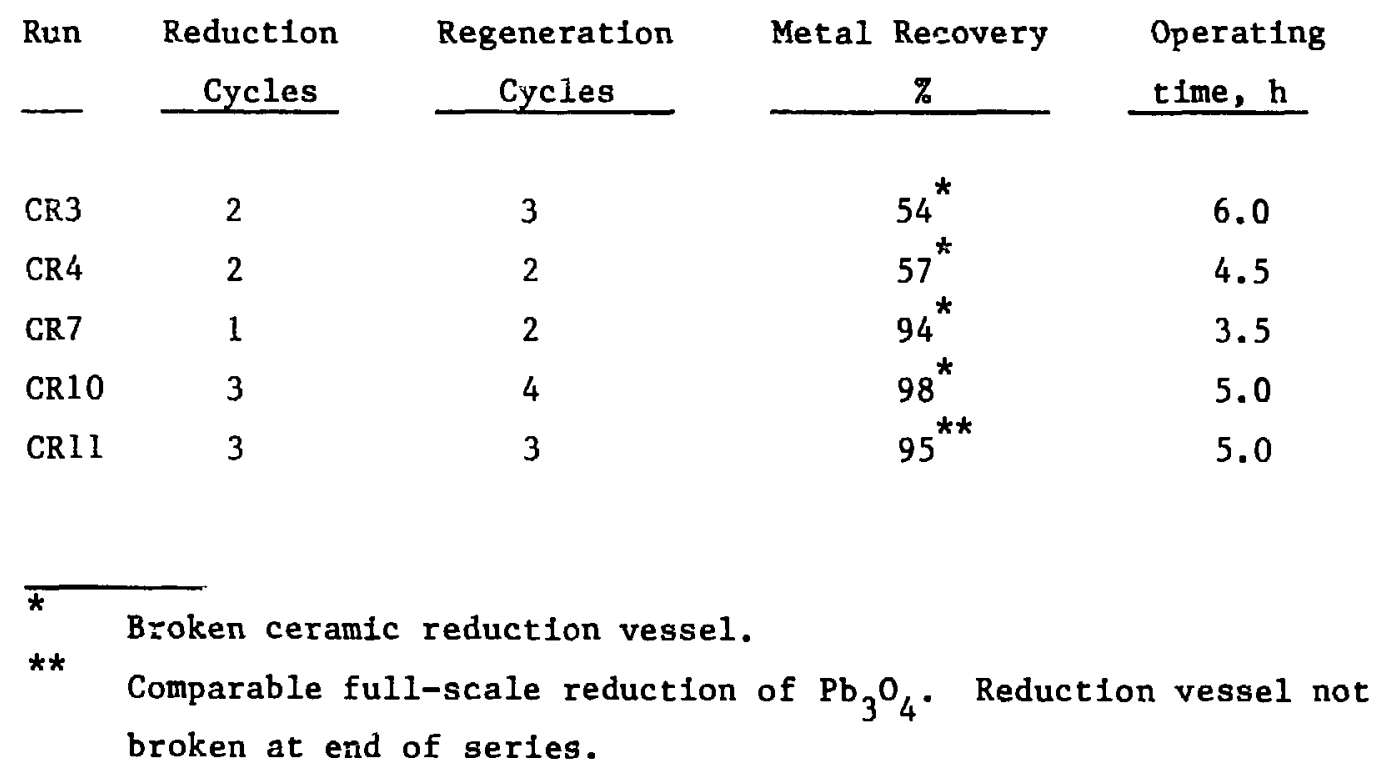


These initial experiments have also been useful in defining certain deficiencies in our process, which are current topics of investigation. These plans include

- impioving reliability in the vacuum-transfer device - we must develop the capability to unplug transfer tubes in the glovebox using no water;

- Investigating compatible metal reaction vessels for oxide reduction and regeneration. The breakage of ceramic vessels in the semicontinuous process interrupts continuity in salt transfer and/or plutonium metal recovery;

0 considering product metal handling alternatives. Can it be allowed to accumulate in the DOR vessel or must it be periodically removed?

\section{FUTURE DIRECTION}

We are transferring batch regeneration and recycle into our production area for long-term process demonstration and evaluation. In conjunction with production demon- stration, we plan to continue investigations into the following areas:

- evaluation of operating parameters; chlorine/argon dilution, regenerácion time, and excess calcium in DOR.

- upgrade of vacuum-transfer tubes for reliable glovebox use.

- investigation of alternate materials of construction for reaction vessels. Both regeneration and oxide reduction vessels should be reusable and compatible with their respective environments.

o design and testing of an external scrubber for treating regeneration off-gas. Material for this system must be compatible with radioactive alkaline, oxidizing chloride solutions. 
o Investigation of senicontinuous metal production techniques. The successful development of a process will depend on answering questions Involving materials compatibility, equipment development, and off-gas handling.

These items must be resolved in order for semicontinuous DOR to be seriously demonstrated in production. Even if our semicontinuous process cannot be developed because of these problems, the batch regeneration and recycle of spent DOR salt w111 remain an attractive alternative for reducing process waste.

\section{ACKNOWLEDGMENTS}

Without the help of dedicated technicians who routinely performed and commented on these experiments, the development of DOR salt recycle would have suffered. For these reasons and more, we would 11ke to thanic A. E. Buchholz, M. J. Chavez, W. K. Drennon, D. W. Anderson, J. Y. Coulter, J. J. Simpson, and B. J. Phillips for their contributions in early development activities.

We would also like to thank personnel at CLS-1, our analytical chemistry group, for their timely and revealing analytical support. Without resuits from the hundreds of salt samples we generated to support this project, process development could not have been accurately accomplished in any reasonable time. 


\section{REFERENCES}

1. D. C. Christensen and L. J. Mullins, "Present Status of Plutonfum Metal Production and Purification at Los Alamos-1982," Los Alisos National Laboratory report LA-9674-MS (June 1983).

2. L. J. Mullins, D. C. Christensen, and B. R. Babcock, "Fused Salt Processing of Impure Plutonium Dij, -de to High-Purity Plutonium Metal," Los Alamos National Laboraiciy report LA-9154-MS (January 1982).

3. M. S. Coops and D. $\vec{F}$. Bowersox, "Nonaqueous Processing Methods," Los Alamos National Laboratory report LA-10169-MS (September 1984).

4. R. E. Barletta et al., "Molten Salt Recycle, Electrolysis of CaO in Molten Salt," Argonne National Laboratory report ANL-79-99 (April 1979).

5. K. W. Fife, D. F. Bowersox, and E. D. McCormick, "Comparison of Phosgene, Chlorine, and Hydrogen Chloride as Reagents for Converting Molten $\mathrm{CaO} \cdot \mathrm{CaCl}_{2}$ to $\mathrm{CaCl}_{2}$," Los Alamos National Laboratory report LA-10523-MS (September 1985).

6. F. H. Ellinger, W. H. Miner, D. R. O'Boyle, and F. W. Schonfeld, "Constitution of Plutonium Alloys," Los Alamos Scientific Laboratory report LA-3870 (December 1968).

7. K. W. Fife, D. F. Bowersox, D. C. Christensen, and J. D. Williams, "The Preparation of Fused Chloride Salts for Use in Pyrochemical Plutonium Recovery Operations at Los Alamos," los Alamos National Laboratory report LA-10681 (July 1986).

8. C. E. C. Rense, K. W. Fife, D. F. Bowersox, and M. D. Ferran, "Materials Compatibility During the Chlorination of Molten $\mathrm{CaCl}_{2} \cdot \mathrm{CaO}$ Salts," Los Alamos National Laboratory report LA-10700-MS (in preparation). 